\title{
FORMULATION AND EVALUATION OF ALGINATE-BASED MUCOADHESIVE BUCCAL PATCH FOR DELIVERY OF ANTIMIGRAINE DRUG
}

\author{
GYATI SHILAKARI ASTHANA ${ }^{1,2 *}$, SUMIT SHARMA ${ }^{2}$, ABHAY ASTHANA ${ }^{2}$ \\ ${ }^{1}$ Department of Bharat Institute of Technology, Mangalpally, Ibrahimpatnam, Hyderabad, Telangana, India. ${ }^{2}$ Department ${ }^{\text {of }}$ \\ Pharmaceutics, MM College of Pharmacy, Maharishi, Markandeshwar University, Mullana, Ambala, Haryana, India. \\ Email: gyatibit@gmail.com
}

Received: 26 December 2017, Revised and Accepted: 01 January 2018

ABSTRACT

Objective: The present work was aimed with enhancement of oral bioavailability of sumatriptan succinate by sodium alginate-based mucoadhesive buccal patches.

Methods: These patches were prepared by solvent-casting method using different concentrations of sodium alginate along with HPMC 5cps and maltodextrin as a film-forming polymer. Propylene glycol, sodium lauryl sulfate, and mannitol were used as plasticizer, penetration enhancer, and filler, respectively. Prepared patches were evaluated with respect to various in vitro parameters and in vivo studies were conducted on white strain New Zealand rabbits of either sex with average weight $2-3 \mathrm{~kg}$

Results: All the formulations were transparent and homogeneous. F7 formulation containing Na alginate (250 mg), maltodextrin (250 mg), and HPMC 5 cps (250 mg) displayed maximum folding endurance, mucoadhesive force, in vitro drug transport, and drug release and found to be stable up to 2 months in storage conditions. The pharmacokinetic parameters such as Cmax, tmax, and AUC were calculated from the data collected after in vivo studies. Sumatriptan succinate containing buccal patch displayed almost 1.73 folds and 2 folds higher Cmax and AUC, respectively, than plain drug solution. $1.93 \%$ of relative bioavailability was reported with the formulation.

Conclusion: The outcome of the present work reveals that sumatriptan succinate-based mucoadhesive buccal formulation can improve overall performance of drug molecule in vitro and in vivo.

Keywords: Sumatriptan succinate, Buccal patch, Muccoadhesion, Sodium alginate, In vivo studies.

(C) 2018 The Authors. Published by Innovare Academic Sciences Pvt Ltd. This is an open access article under the CC BY license (http://creativecommons. org/licenses/by/4. 0/) DOI: http://dx.doi.org/10.22159/ajpcr.2018.v11i4.23345

\section{INTRODUCTION}

Sumatriptan succinate is an antimigraine drug which is the first triptan drug and is the most potent among all triptans. It is a selective 5-HT1D receptor agonist that can contract intracranial artery and redistributes blood and improve cerebra blood flow. It affects a certain natural substance known as serotonin that causes narrowing of blood vessels in the brain. It may also relieve pain by affecting certain nerves in the brain [1] The drug undergoes high first-pass metabolism and incomplete absorption, which results in its very low oral bioavailability that is only $15 \%[2]$.

Commercially, sumatriptan succinate is available as conventional tablets, parenteral injections, and intranasal solution. However, these peroral formulations are associated with some limitations such as first-pass metabolism, enzymatic degradation and $\mathrm{pH}$-dependent solubility which decrease the efficiency and therapeutic effect of medication [3].

Buccal route is a very favorable route of administration due to its numerous advantages over peroral routes of administration. Patient compliance is one of the major advantages of this route. It is a more acceptable route for pediatric, geriatric, and other patients who have trouble in swallowing the solid dosage forms due to fear of choking and fear of pain due to the injections. Buccal route is also favorable for patients due to ease of administration and termination or withdrawal of therapy [4]. First-pass metabolism, enzymatic degradation, and pH-dependent solubility are some of the major limitations associated with peroral routes that decrease the efficiency and therapeutic effect of medication [5]. Buccal drug delivery is the most preferred route due to its high relative permeability from the other routes which is the result of the rich blood supply in this region. Furthermore, for the drugs having a high first-pass metabolism or enzymatic degradation, this route is a favorable option as it releases the drug directly into systemic circulation, thereby avoiding such degradation [6]. Moreover, rapid absorption of drugs through buccal route can result in rapid onset of action which is required in many cases [7]. Therefore, buccal drug delivery system is one of the potential systems for delivery of certain drug candidates due to the flexibility and attractiveness of this system.

Many technologies have been reported for delivery of a wide variety of drugs using buccal route, including buccal bioadhesive tablets [8], buccoadhesive patches and films [9], buccoadhesive semisolid dosage forms, and buccoadhesive powder dosage forms [10]. Mucoadhesive buccal patches are thin films or patches which get adhered to the mucous membrane in buccal cavity, dissolves by saliva and release drug for oral mucosal absorption Mucoadhesive buccal patches has numerous advantages such as ease of administration, mucoadhesive buccal patches are too thin hence, have greater comfort level than other formulations, require less amount of saliva for wetting, light in weight- easy for transportation excellent stability and absorption, facility to include penetration enhancer to increase therapeutic efficiency of drug [9,11], availability in various sizes, convenient and accurate dosing, taste masking, rapid dissolving patches can exhibit rapid onset of action and options to design unidirectional or bidirectional release films by which releasing action can be controlled [12] Therefore, this technology can be useful to improve therapeutic efficacy of drugs like sumatriptan succinate. 
The present study was undertaken with an objective to address various issues related to drug such as first-pass metabolism and low oral bioavailability. Sumatriptan succinate containing mucoadhesive buccal patches using sodium alginate in different concentrations was prepared and evaluated for various in vitro, physicochemical parameters, in vitro release study, mucoadhesion force, mucoadhesion time, stability, and in vivo studies. Advanced novel approach for delivery of sumatriptan succinate as mucoadhesive buccal patches could extend the opportunity to avail efficient delivery of drug

\section{METHODS}

Sumatriptan succinate was received as gift sample from Dr. Reddy's Laboratory, Hyderabad. Na alginates, maltodextrin, HPMC 5 cps, propylene glycol, sodium lauryl sulfate, and mannitol were purchased from Sigma-Aldrich, Bengaluru, India.

\section{Drug and excipient compatibility study}

A drug excipient interaction study was carried out using a Fouriertransform infrared (FTIR) spectrophotometer by $\mathrm{NaCl}$-press pallet method to check any interaction between drug and excipient. The sample of the drug was mixed with different excipient, filled in screw cap amber color vials, then labeled and stored in different storage conditions room, freezer, and accelerated temperature for 2 months. The samples were subjected to visual observation and FTIR

\section{Preparation of mucoadhesive buccal patches}

Mucoadhesive buccal patches of sumatriptan succinate were prepared by solvent casting method as reported earlier with slight modification [13]. Aqueous solution was prepared by dissolving accurately weighted amounts of polymers by magnetic stirring. Then, propylene glycol (plasticizer), filler (mannitol), and drug were added and mixed. The obtained solutions were then cast into Petri dishes, previously cleaned and dried. Plates were then kept in oven at $50^{\circ} \mathrm{C}$ for $24 \mathrm{~h}$. Dried films were carefully removed, checked for any flaws, and cut into square pieces of required dimensions for evaluation purpose using a sharp-bladed cutter. Patches were individually sealed in airtight containers at room temperature for storage. Composition of different buccal patch formulations is given in Table 1 .

\section{Characterization of buccal patches}

Sumatriptan succinate containing buccal patches were prepared using various concentrations of polymers as shown in Table 1. The developed formulations were characterized with respect to parameters such as appearance, peelability, thickness, weight uniformity, folding endurance, drug content uniformity, swelling index, mucoadhesion time, mucoadhesive strength, in vitro drug transport, in vitro dissolution study, and stability studies.

\section{Physical appearance}

The buccal patch formulations were observed visually for their physical appearance such as color, transparency, texture, and homogeneity.

\section{Peelability}

After drying of films in oven at $50^{\circ} \mathrm{C}$ for $24 \mathrm{~h}$, they were peeled off from the Petri plate. Thus, peelability of films was checked, whether they get easily peeled off or not [14].

\section{Thickness}

The film was measured for its thickness with the help of Vernier calliper at five different locations of the same film [15].

\section{Weight uniformity}

$1 \mathrm{~cm}^{2}$ of film samples representing five different regions were cut off with the help of a cutter. They were weighed individually to evaluate the uniformity of film [15].

\section{Folding endurance}

To measure folding endurance of patch, its small strip was sliced out in size $2 \mathrm{~cm}^{2}$ from each formulation and was folded in the same place till it breaks. This value gives the folding endurance of film. The higher the number of folds, higher is the folding endurance of film [16].

\section{Drug content uniformity}

$1 \mathrm{~cm}^{2}$ of the film sample representing five different regions were cut off. Patches were individually dissolved in $10 \mathrm{ml}$ PBS 6.8 and stirred for 30 min. Then, the sample was filtered and analyzed using a ultraviolet (UV) spectrophotometer at $\lambda \max 284 \mathrm{~nm}$ [17].

\section{Surface $\mathrm{pH}$ studies}

Buccal patches were allowed to swell for $2 \mathrm{~h}$ on the surface of the agar plate (prepared by dissolving $2 \% \mathrm{w} / \mathrm{v}$ agar in warm isotonic phosphate buffer $\mathrm{pH} 6.8$ under stirring, then poured the solution into a petri dish till it gelled at room temperature. The surface $\mathrm{pH}$ was measured by bringing a combined glass electrode in contact with the surface of the patch. The average of three readings was recorded [18].

\section{Swelling index}

To determine swelling, index three patches of $1 \mathrm{~cm}^{2}$ were sliced from different regions of the same film and weighed individually (w1). Patches were immersed in $\mathrm{pH} 6.8 \mathrm{PBS}$ at $37^{\circ} \mathrm{C}$ for $2 \mathrm{~h}$. Then, patches were weighed at the end of $2 \mathrm{~h}$ (w2). The swelling index was calculated using the following equation:

Swelling index $=[\{(w 2-w 1) / w 1\} 100]$.

\section{In vitro mucoadhesion time}

In vitro mucoadhesion time of patches was evaluated by assessing the time for patches to detach from the porcine buccal mucosa. The porcine buccal mucosa was bought from a local butcher house and fixed to the wall of well-stirred beakers containing $50 \mathrm{ml}$ of artificial saliva maintained at $37^{\circ} \mathrm{C}$ as shown in Fig. 1 . The patch was wetted with $50 \mu \mathrm{l}$ of artificial saliva and adhered to a membrane by applying a light force with a fingertip for $1 \mathrm{~min}$. The time required for detachment of these patches from buccal mucosa was recorded and taken as in vitro mucoadhesion time [18].

\section{In vitro mucoadhesion strength}

It was measured on the modified physical balance. It consists of modified double-beam physical balance as shown in Fig. 2. A petri dish containing $7.5 \mathrm{ml}$ artificial saliva pH 6.8 was placed below the left pan. Porcine mucosa was used as model membrane and artificial saliva pH 6.8 was used as moistening fluid. The membrane was kept in Krebs's solution at $37^{\circ} \mathrm{C}$ for $2 \mathrm{~h}$. The underlying mucous membrane was separated and

Table 1: Composition of mucoadhesive buccal patch formulations

\begin{tabular}{|c|c|c|c|c|c|c|c|c|c|}
\hline $\begin{array}{l}\text { Formulation } \\
\text { codes }\end{array}$ & $\begin{array}{l}\text { Na alginate } \\
\text { (mg) }\end{array}$ & $\begin{array}{l}\text { Malto dextrin } \\
\text { (mg) }\end{array}$ & $\begin{array}{l}\text { HPMC 5cps } \\
\text { (mg) }\end{array}$ & $\begin{array}{l}\text { Propylene } \\
\text { glycol (ml) }\end{array}$ & $\begin{array}{l}\text { Mannitol } \\
\text { (mg) }\end{array}$ & $\begin{array}{l}\text { Water } \\
\text { (ml) }\end{array}$ & Drug (mg) & SLS (mg) & Aspartame (mg) \\
\hline F1 & 200 & - & - & 3 & 6 & 17 & 50 & 5.063 & 10 \\
\hline $\mathrm{F} 2$ & 250 & - & - & 3 & 6 & 17 & 50 & 5.063 & 10 \\
\hline F3 & 300 & - & - & 3 & 6 & 17 & 50 & 5.063 & 10 \\
\hline $\mathrm{F} 4$ & 400 & - & - & 3 & 6 & 17 & 50 & 5.063 & 10 \\
\hline F5 & 500 & - & - & 3 & 6 & 17 & 50 & 5.063 & 10 \\
\hline F6 & 600 & - & - & 3 & 6 & 17 & 50 & 5.063 & 10 \\
\hline
\end{tabular}


washed thoroughly with $\mathrm{pH} 6.8$ artificial saliva. This was then fixed to a glass slide by a bioadhesive tape. The patches were stocked at the bottom of the left pan. $3 \mathrm{~g}$ weight was placed in both the pans. The left pan gets lowered placing film in contact with mucous membrane under the weight of $5 \mathrm{~g}$ placed on it. It is kept undisturbed for $2 \mathrm{~min}$. Then, weight on the right-hand side pan was slowly added in an increment of $0.5 \mathrm{~g}$ till film gets separated from the membrane surface. The excess weight on the right-hand side of pan that is total weight minus $5 \mathrm{~g}$ was taken as a measure of mucoadhesive strength [19]. Force of adhesion was calculated using the following equation.

Force of adhesion $=$ Bio adhesive strength $\times 9.81 / 1000$

\section{In vitro drug transport}

In vitro drug transport study was carried out using Franz diffusion cell comprised of receptor compartment, donor compartment, sampling port, and outer jacket. Volumes of the donor and receptor compartment were kept $3 \mathrm{ml}$ and $5 \mathrm{ml}$, respectively. Receptor chamber was filled with $5 \mathrm{ml}$ of PBS 6.8 and placed on a magnetic stirrer with a Tefloncoated magnetic bead placed on the base of receptor compartment and maintained at $37 \pm 1^{\circ} \mathrm{C}$. The porcine buccal mucosa was used as a model for permeation study. It was mounted on the mouth of the receptor chamber of the Franz diffusion cell and equilibrated for an hour using artificial saliva. After equilibration, $3 \mathrm{ml}$ of artificial saliva $\mathrm{pH} 6.8$ was added to donor compartment. Assembly was clamped with holder and diffusion was carried out for 2 h. $0.3 \mathrm{ml}$ sample was withdrawn at predetermined time intervals from receptor compartment through sampling port and replaced with an equal volume of media. Withdrawn sample was analyzed by UV spectrophotometer at $\lambda \max 284 \mathrm{~nm}$ [20].

\section{In vitro drug release}

In vitro dissolution study was carried out in USP apparatus 1 using 300 $\mathrm{ml}$ of PBS pH 6.8 as dissolution media. One film section of $4 \mathrm{~cm}^{2}$ area was cut out and placed in each basket. Dissolution was carried out at $50 \mathrm{rpm}$ on $37 \pm 0.5^{\circ} \mathrm{C}$. Samples were withdrawn at fixed time points up to $2 \mathrm{~h}$, and equal amount of PBS was replaced to maintain the sink conditions. Collected samples were analyzed by UV spectrophotometer to calculate drug content and percent drug release [21].

\section{Stability study}

On the basis of the results of in vitro characterization, F7 was selected for further stability and in vivo studies. Stability study was carried out at room temperature and accelerated conditions for 2 months. Samples were stored in amber colored vials and analyzed after $1^{\text {st }}$ week, $2^{\text {nd }}$ week, $1^{\text {st }}$ month, and $2^{\text {nd }}$ month. The samples were analyzed with respect to physical appearance and drug content [22].

\section{In vivo study}

The present work was dually approved by the Animal Ethical Committee CPCSA No MMCP/IAEC/15/10 to conduct in vivo. New Zealand white strain rabbits of either sex were selected for in vivo studies. The animals were fasted overnight before the formulation administration. The weight of the individual animal was taken. Animals were divided into two groups. The dose was calculated according to their body weight, $0.75 \mathrm{mg}$ of plain drug was dissolved in distilled water and administered to $1^{\text {st }}$ group through gastric gavages. Patch equivalent to $0.75 \mathrm{mg}$ of plain drug was subjected to $2^{\text {nd }}$ group. Blood samples were collected in heparinized tubes from the tail vein at predetermined time points
$(0.25,0.5,1,2,6$, and after $24 \mathrm{~h})$, and plasma was separated out by centrifugation at $2000 \mathrm{rpm}$ for $5 \mathrm{~min}$. The drug concentration in plasma was determined by UV spectrophotometer [16].

\section{RESULTS AND DISCUSSION}

\section{Drug and excipient compatibility study}

Drug-excipient compatibility study was performed using FTIR spectroscopy to establish any possible interaction of drug, sumatriptan succinate with the polymeric excipient used in the formulation. The FTIR spectrum of the physical mixture was compared with the FTIR spectra of the pure drug and chitosan kept at RT $\left(25^{\circ} \mathrm{C}\right)$ on the $15^{\text {th }}$ day. The results indicated that the characteristic absorption peaks of all functional groups such as sulfonamides, $\mathrm{C}=\mathrm{O}$, and $\mathrm{C}-\mathrm{H}$ stretching of pure sumatriptan succinate have appeared in the physical mixture without noticeable change in their positions indicating no chemical interaction between sumatriptan succinate and polymers (Fig. 3a-d)

\section{Physical appearance}

It was observed from the results as shown in Fig. 4 that all the formulations were transparent.

\section{Homogeneity}

Homogeneity of all the formulations was determined and displayed in Table 2 . All the formulations were homogenous by physical appearance, and no particulates were visible in films.

\section{Peelability}

Formulations $\mathrm{F} 1$ and $\mathrm{F} 2$ were broken during peeling due to low tensile strength, whereas formulations F3, F4, F5, F6, and F7 displayed good peelability as shown in Table 2. This may be due to increase in polymer concentration unless it thickens too much due to higher polymer concentration [17].

\section{Thickness}

Thickness of the films was determined by digital Vernier calliper and the results were shown in Table 2. All the films lie in the range of
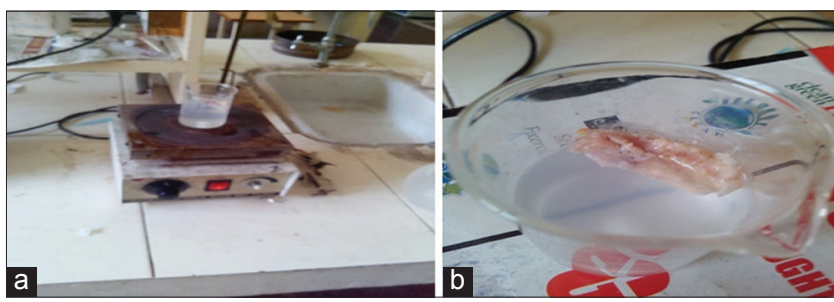

Fig. 1: ( $a$ and $b$ ) Determination of in vitro mucoadhesion time using porcine buccal mucosa

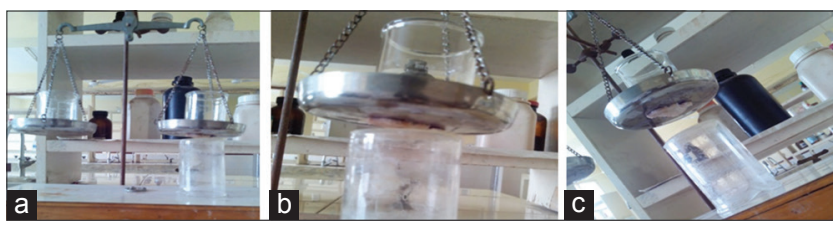

Fig. 2: (a-c) Experimental setup to determine in vitro mucoadhesive force

Table 2: Physical characteristics of different formulations

\begin{tabular}{|c|c|c|c|c|}
\hline Formulation codes & Homogeneity & Transparency & Thickness (mm) & Peelability \\
\hline F1 & Homogenous & Transparent & 0.1 & Break at peeling \\
\hline $\mathrm{F} 2$ & Homogenous & Transparent & 0.1 & Break at peeling \\
\hline F3 & Homogenous & Transparent & 0.1 & Not peeled off easily \\
\hline $\mathrm{F} 4$ & Homogenous & Transparent & 0.1 & Easily peeled off \\
\hline F5 & Homogenous & Transparent & 0.2 & Easily peeled off \\
\hline F6 & Homogenous & Transparent & 0.3 & Easily peeled off \\
\hline F7 & Homogenous & Transparent & 0.1 & Easily peeled off \\
\hline
\end{tabular}




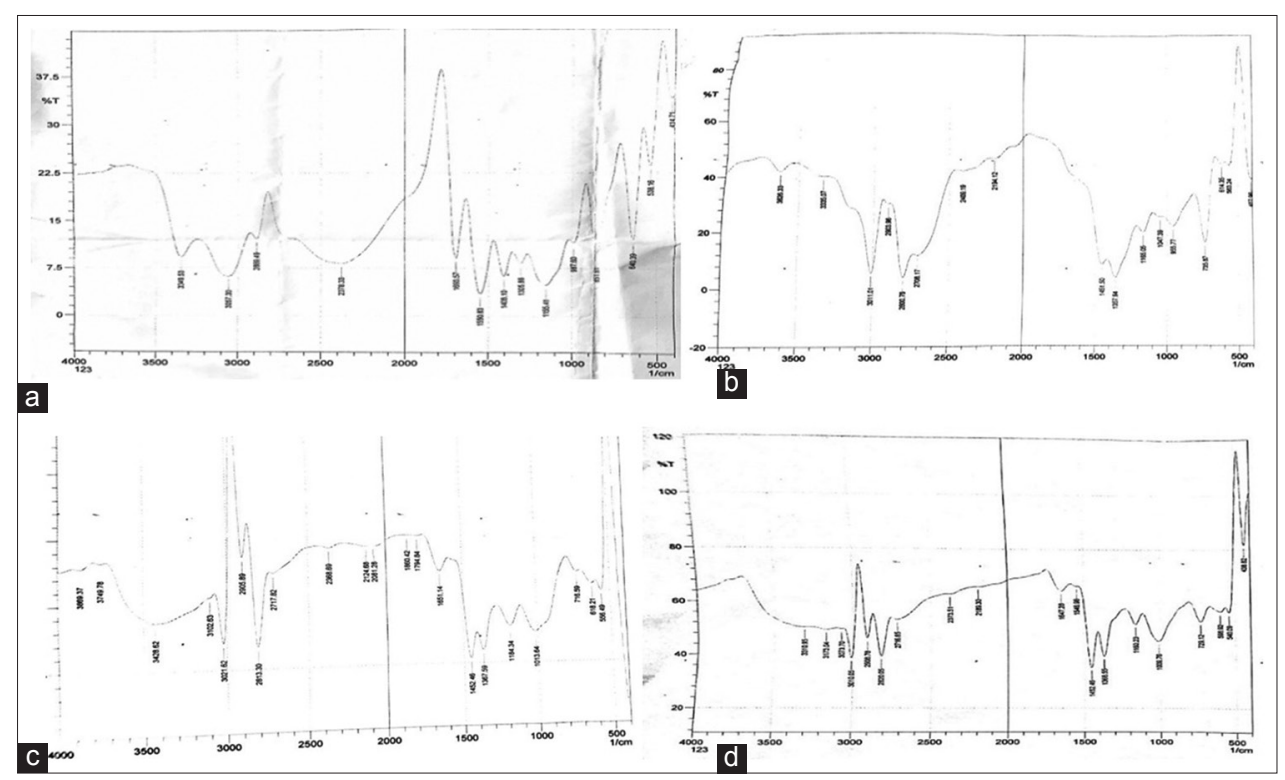

Fig. 3: Fourier-transform infrared spectra of (a) sumatriptan succinate, (b) physical mixture of drug and Na alginate, (c) physical mixture of drug and HPMC, and (d) physical mixture of drug maltodextrin

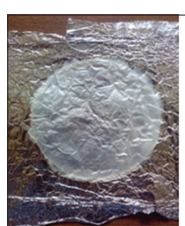

F3

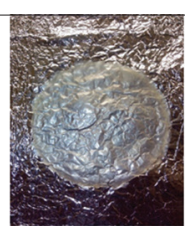

F4

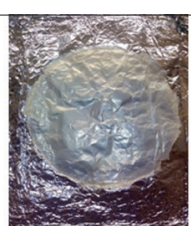

F5

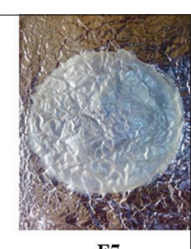

F-7

Fig. 4: Physical appearances of various buccal patch formulations

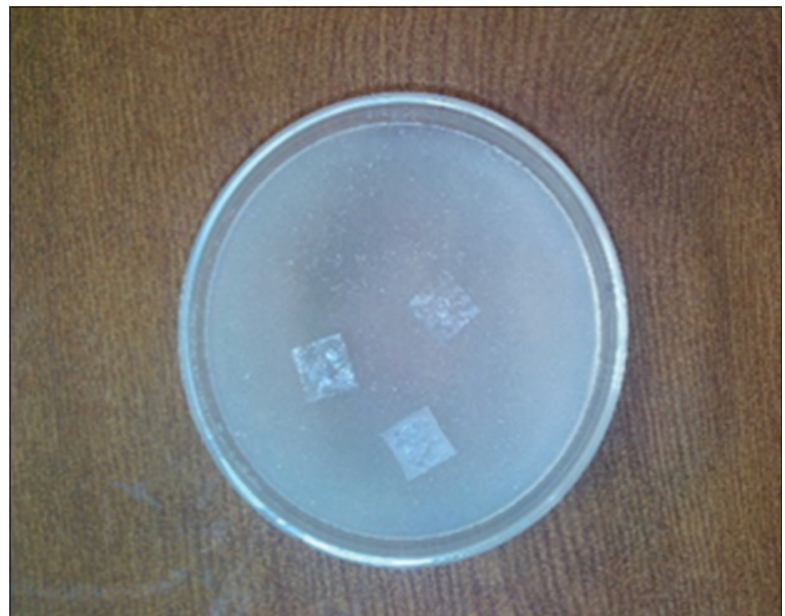

Fig. 5: Swelling study of buccal patch

$0.10 .3 \mathrm{~mm}$. Formulation $\mathrm{F} 6$ was found to be $0.3 \mathrm{~mm}$ thick, whereas all the other formulations had a desirable thickness $(0.1-0.2 \mathrm{~mm})$.

\section{Folding endurance}

The formulations were evaluated for their folding endurance by folding all the films from the same place until they break and results were displayed in Table 3. It was observed from the data that folding endurance of the films was decreased by increasing the concentration of polymer (sodium alginate). Formulation F7 shows highest folding endurance among all the formulations which contain sodium alginate, maltodextrin, and HPMC 5cps. This may be due to the presence of HPMC 5 cps that has the high elongation ability due to its high viscosity and cross-linked structure. The folding endurance of various patch formulations was founded in the order of F7 $>$ F3 $>$ F4 $>$ F5 $>$ F6.

Formulation F6 displayed poor folding endurance, possibly due to the presence of high concentration of polymer. Therefore, it was discarded from further evaluations.

\section{Weight uniformity}

Weight uniformity of various formulations was determined and results were shown in Table 3. Formulations F1 and F2 were discarded as these formulations were broken during peeling. Weight uniformity of all the formulations was lying in the range of $9 \mathrm{mg} / \mathrm{cm}^{2}-14.98 \mathrm{mg} / \mathrm{cm}^{2}$.

\section{Percent drug content uniformity}

Drug content uniformity was evaluated from five sample patches dissolved in PBS, pH 6.8 for 30 min, and analyzed spectrophotometrically. It was clearly observed from the data as presented in Table 3 that more than $97 \%$ drug content uniformity was reported for all the formulations. The highest $98.78 \pm 0.01 \%$ drug content uniformity was recorded with F7 formulation.

\section{Surface pH studies}

Surface $\mathrm{pH}$ was calculated by bringing the swelled sample in contact with the combined glass electrode. Characterization was done in triplets, and surface $\mathrm{pH}$ of all the formulations was lying in the range 6.9-7.2 as summarized in Table 3.

\section{Swelling index}

Swelling index was calculated as per its formula given in the literature and the results were given in Fig. 5 and Table 3. Swelling indices of different formulations lie in the range 0.053-0.079. Increase in polymer concentration led to increase in the extent of swelling of the patches [17]. All the formulations show good swelling characteristics.

\section{In vitro mucoadhesion time}

In vitro mucoadhesion time was determined by the procedure discussed earlier in materials and methods with porcine mucosa as model membrane. The results were shown in Table 4. From the results, it was observed that mucoadhesion time of all the formulations was found between the ranges of 20 and $33 \mathrm{~min}$. Among all the formulations, not a single sample patch loses its mucoadhesion in respective time until they got completely dissolved in artificial saliva.

\section{In vitro mucoadhesive strength}

In vitro mucoadhesive strength of formulations was determined by modifying balance technique as shown in Fig. 1 and porcine buccal 
Table 3: Folding endurance, weight uniformity, drug content uniformity, surface pH, and swelling indices of formulations

\begin{tabular}{|c|c|c|c|c|c|}
\hline $\begin{array}{l}\text { Formulation } \\
\text { codes }\end{array}$ & $\begin{array}{l}\text { Folding } \\
\text { endurance (folds) }\end{array}$ & Weight uniformity $\left(\mathrm{mg} / \mathrm{cm}^{2}\right)$ & Swelling index & Surface pH & Drug content uniformity (\%) \\
\hline F3 & 910 & $14.066 \pm 0.6$ & $0.0532 \pm 0.003$ & $6.9 \pm 0.54$ & $98.59 \pm 0.003$ \\
\hline $\mathrm{F} 4$ & 680 & $13.5 \pm 0.4$ & $0.063 \pm 0.002$ & $6.7 \pm 0.39$ & $98.12 \pm 0.009$ \\
\hline F5 & 454 & $14.033 \pm 0.23$ & $0.072 \pm 0.008$ & $7.2 \pm 0.66$ & $97.47 \pm 0.002$ \\
\hline F6 & 364 & $14.98 \pm 0.52$ & $0.076 \pm 0.002$ & $6.9 \pm 0.27$ & $98.25 \pm 0.006$ \\
\hline F7 & 1265 & $9.8 \pm 0.24$ & $0.079 \pm 0.006$ & $7.2 \pm 0.23$ & $98.78 \pm 0.01$ \\
\hline
\end{tabular}

mucosa was used as model membrane. It was observed from results as depicted in Table 4 that the mucoadhesive strength of formulations was increased with increasing the concentration of polymer. This may be due to contact of more polymer to tissue surface [19]. The mucoadhesive strength of all the formulations lies in the range of $18-40 \mathrm{~g}$.

\section{In vitro dissolution study}

In vitro dissolution study was carried out using USP dissolution apparatus 1 in PBS, pH 6.8, and results are shown in Fig. 6. 90- 98\% drug release was reported with all the formulations after $2 \mathrm{~h}$. Formulations F7 displayed the highest amount of drug release as compared to other formulations at each time point. This may be due to the relatively less amount of sodium alginate in formulation F7 than other formulations.

\section{Percent in vitro drug transport}

In vitro permeation study was carried out using Franz diffusion cell up to $2 \mathrm{~h}$ and results are shown in Fig. 7. From the results, it was observed that formulation F7 shows maximum in vitro drug transport of $36.3 \%$ after $2 \mathrm{~h}$, this might be due to complete dissolution in $2 \mathrm{~h}$, as observed earlier in dissolution rate data. This further indicates that dissolution of the drug is critical to in vitro drug transport.

\section{Selection of mathematical model}

Drug release kinetics

The drug release study was further investigated in the kinetic studies. Various kinetic models such as zero order, first order, Higuchi, and Peppas were applied for kinetic studies and $\mathrm{R}^{2}$ values were noted. The maximum $\mathrm{R}^{2}$ value was reported for the first-order model as shown in Table 5 and Fig. 8. Hence, it follows first-order kinetics.

\section{Stability study}

On the basis of the results of in vitro characterization of the developed formulations, F7 was selected for further stability studies and in vivo studies. $\mathrm{F} 7$ formulation was kept under room temperature and accelerated conditions for 2 months. Samples were withdrawn after the initial time period and $1^{\text {st }}$ week, $2^{\text {nd }}$ week, $1^{\text {st }}$ month, and $2^{\text {nd }}$ month. Physical appearance of formulation was observed, and drug content was determined by UV spectrophotometer. There was no difference in the physical appearance of the formulation. The drug content of formulation F7 was found to be $98.04 \%$ and $97.99 \%$ after 2 months of storage conditions of room temperature and accelerated conditions (Fig. 9). Formulation F7 was found to be stable in both the conditions at the end of the study.

\section{In vivo studies}

In vivo study of the present work was dually approved by the Animal Ethical Committee CPCSA No MMCP/IAEC/15/10. In vivo studies of F7 formulation and plain drug were performed in normal, healthy New Zealand rabbits to observe drug delivery potential of developing mucoadhesive patches for buccal administration and the results were shown in Fig. 10. Plasma concentration-time profile of sumatriptan succinate was generated by plotting a graph between percent drug plasma concentration versus time. Higher plasma drug concentration at each time point was observed with developed mucoadhesive buccal patches as compared to plain drug solution. Various pharmacokinetic
Table 4: In vitro mucoadhesive time and mucoadhesive strength of different formulations

\begin{tabular}{lll}
\hline $\begin{array}{l}\text { Formulation } \\
\text { codes }\end{array}$ & $\begin{array}{l}\text { In vitro mucoadhesion } \\
\text { time (min) }\end{array}$ & $\begin{array}{l}\text { In vitro mucoadhesive } \\
\text { force }(\mathrm{g}) \pm(\mathbf{S D})\end{array}$ \\
\hline F3 & $25.3 \pm 0.46$ & $18.2 \pm 0.6$ \\
F4 & $31.8 \pm 0.29$ & $23.5 \pm 0.9$ \\
F5 & $32.9 \pm 0.32$ & $28.6 \pm 0.4$ \\
F7 & $20.9 \pm 0.21$ & $39.1 \pm 0.5$ \\
\hline
\end{tabular}

$\mathrm{n}=3$

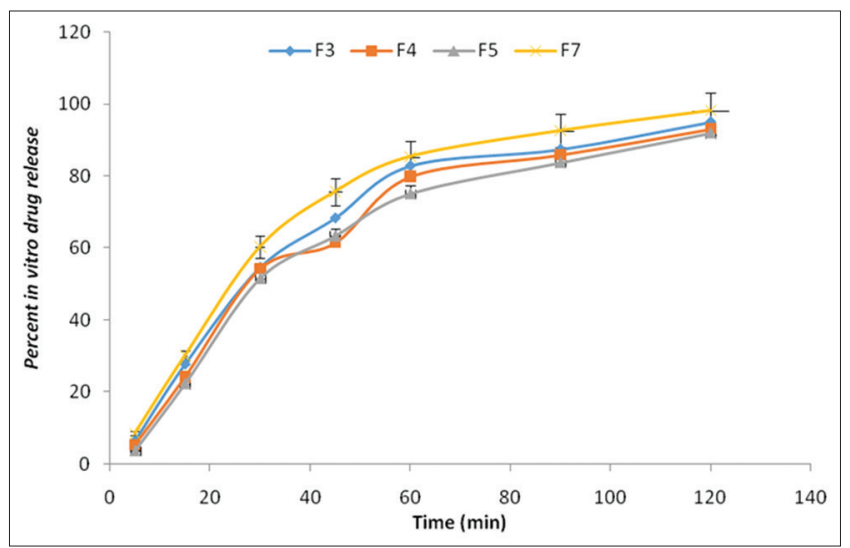

Fig. 6: In vitro drug releases of various buccal patch formulations in PBS 6.8

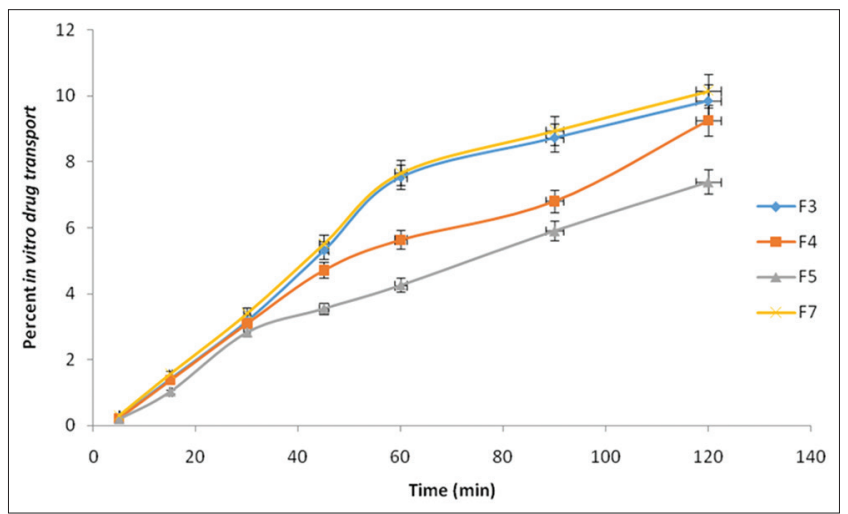

Fig. 7: In vitro drug transports of different buccal patch formulations

parameters such as $\mathrm{C}_{\text {max }}, \mathrm{t}_{\text {max }}$ and AUC were calculated from the plasma concentration-time profile. Formulation F7 of sumatriptan succinate displayed almost 1.73 folds higher Cmax (peak plasma concentration) than plain drug solution. Both formulations attain Cmax at 60 min after administration. The AUC value of formulations was found to be approximately 2 folds higher as compared to plain drug solution. Relative bioavailability was found to be $1.93 \%$ (Table 6). 


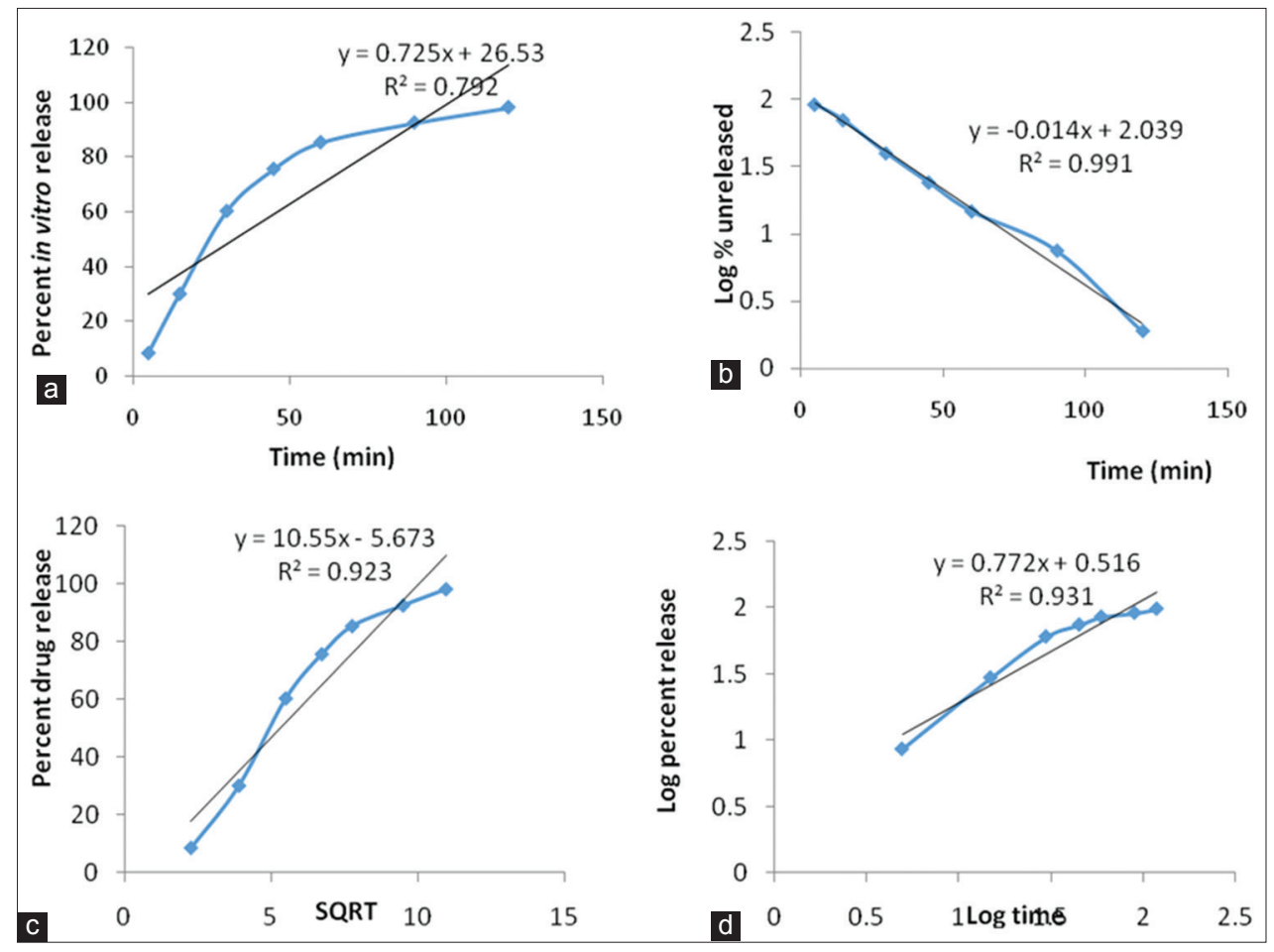

Fig. 8: Kinetic release of the F7 formulation by different models (a) zero order, (b) first order (c) Higuchi, (d) Krosemeyer Peppas model

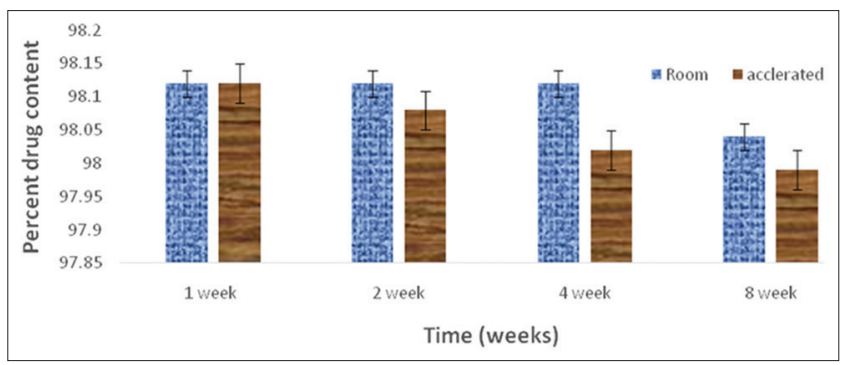

Fig. 9: Stability study of F7 Formulation

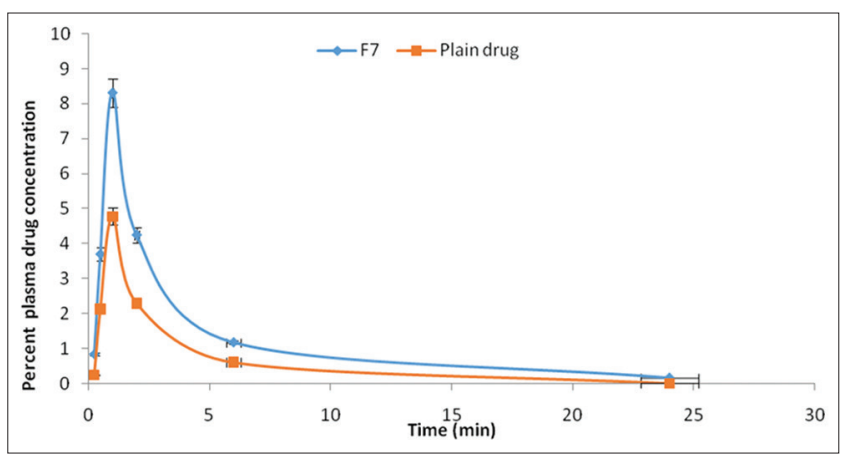

Fig. 10: Plasma drug concentration-time profiles of F7 formulation and plain drug

\section{CONCLUSIONS}

In the present work, buccal patch of sumatriptan succinate was developed successfully in terms of its acceptability as a novel dosage form. The study reveals that Na alginate-based mucoadhesive buccal patches of sumatriptan succinate along with HPMC $5 \mathrm{cps}$, maltodextrin, and sodium lauryl sulfate greatly improve its performance with respect to overcoming key issues related to drug's bioavailability. The outcome of the present study reveals that buccal administration of sumatriptan
Table 5: Drug release mechanism

\begin{tabular}{lllccc}
\hline $\begin{array}{l}\text { Formulation } \\
\text { code }\end{array}$ & $\begin{array}{l}\text { Zero } \\
\text { order } \\
\mathbf{R}^{2}\end{array}$ & $\begin{array}{l}\text { First } \\
\text { order } \\
\mathbf{R}^{2}\end{array}$ & $\begin{array}{l}\text { Higuchi } \\
\text { Model } \\
\mathbf{R}^{2}\end{array}$ & $\begin{array}{l}\text { Korsmeyer } \\
\text { Peppas } \mathbf{R}^{2}\end{array}$ & $\begin{array}{l}\text { Best fit } \\
\text { model }\end{array}$ \\
\hline F7 & 0.7929 & 0.9916 & 0.9233 & 0.9312 & $\begin{array}{l}\text { First } \\
\text { order }\end{array}$ \\
\hline
\end{tabular}

Table 6: Pharmacokinetic parameters of optimized formulation and plain drug

\begin{tabular}{lll}
\hline Pharmacokinetic parameters & Formulation F7 & Plain drug \\
\hline $\mathrm{C}_{\text {max }}(\%)$ & 8.31 & 4.78 \\
$\mathrm{~T}_{\max } \mathrm{h}$ & $1 \pm 0.02$ & $1 \pm 0.045$ \\
$\mathrm{AUC}_{0-24}(\mu \mathrm{g} \cdot \mathrm{hr} / \mathrm{mL})$ & $33.2 \pm 0.72$ & $17.19 \pm 0.31$ \\
\hline
\end{tabular}

succinate could enhance the bioavailability through bypassing its firstpass metabolism when given through the oral route. The mucoadhesive buccal patch could be the potential delivery tool for drugs bearing firstpass metabolism.

\section{ACKNOWLEDGMENT}

Author was thankful to Dr. Reddy's laboratory Pvt. Ltd. to provide me with a gift sample of Sumatriptan Succinate. Author was also thankful to Maharishi Markandeshwar University for providing research facilities to carry out this work.

\section{REFERENCES}

1. Sigma-Aldrich. Martindale: The Complete Drug Reference. $33^{\text {rd }}$ ed. London: Sigma-Aldrich; 2002. p. 313-34.

2. Darekar SS, Khadabadi SS, Shahi SR. Formulation and evaluation of bilayer buccal tablet of sumatriptan succinate. Int J Pharm Pharm Sci 2014;6:469-75.

3. Shivanand K, Raju S, Nizamuddin S, Jayakar B. In vivo bioavailability studies of sumatriptan succinate buccal tablets. Daru 2011;19:224-30.

4. Miller N, Johnston T. The use of mucoadhesive polymers in buccal drug 
delivery. Adv Drug Del Rev 2005;57:1666-91.

5. Khairnar A, Sayyad F. Development of buccal drug delivery system based on mucoadhesive polymer. Int J Pharm Tech Res 2010;2:719-35.

6. Amir HS. Buccal Mucosa as a route for systemic drug delivery: A review. J Pharm Pharm Sci 1998;1:15-30.

7. Arya A, Amrish C, Sharma V, Kamla P. Fast dissolving oral films: An innovative drug delivery system and dosage form. Int J ChemTech Res 2010;2:576-83.

8. Balagani PK, Pallepati KK, Jyothshna D. Formulation design and evaluation of mucoadhesive buccal tablets of nitroglycerin. Int J Pharm Pharm Sci 2014;6:251-59.

9. Himabindu P, Mohan CK, Nagaraj B. Design and in vitro characterization of mucoadhesive buccal patches Of duloxetine hydrochloride. Int J Pharm Pharm Sci 2017;9:53-9.

10. Rajesh M, Kishor D, Raj WU, Shripal A. Review on study of buccal drug delivery system. Innov Syst Design Eng 2011;2:24-35.

11. Patil SL, Mahaparale RR, Shivnikar MA, Tiwari SS, Pawar KV, Sane PN. Fast dissolving oral films: An innovative drug delivery system. Int J Res Rev Pharm Appl Sci 2012;2:482-49.

12. Hoogstraatea AJ, Wertza WP, Philip WW. Drug delivery via thebuccal mucosa. Pharm Sci Tech Today 1998;1:309-16.

13. Koland M, Sandeep VP, Charyulu NR. Fast dissolving sublingual films of ondansetron hydrochloride; Effect of additives on in vitro drug release and mucosal permeation. J Young Pharm 2010;2:216-22.

14. Sayed S, Ibrahim HK, Mohamed MI, El-Milligi MF. Fast-dissolving sublingual films of terbutaline sulfate: Formulation and in vitro/in vivo evaluation. Mol Pharm 2013;10:2942-7.

15. Attama AA, Akpa PA, Onugwu LE, Igwilo G. Novel bucco adhesive delivery system of hydrochlorothiazide formulated with ethyl cellulose hydroxypropyl methylcellulose interpolymer complex. Sci Res Essays 2008;3:343-47.

16. Kumar SK, Maddi VN, Rao KR, Bhikshapathi DV. Preparation and in vivo evaluation of oral dissolving films containing sumatriptan succinate. Pharm Lett 2013;3:27-38.

17. Shidhaye SS, Saindane NS, Sutar S, Kadam V. Mucoadhesive bilayered patches for administration of sumatriptan succinate. AAPS PharmSci Tech 2008;9:909-16.

18. Nafee NA, Boraie MA, Ismail FA, Mortada LM. Design and characterization of mucoadhesive buccal patches containing cetylpyridinium chloride. Acta Pharm 2003;53:199-212

19. Bogataj M, Vovk T, Kerec M, Dimnik A, Grabnar I, Mrhar A. The correlation between zeta potential and mucoadhesion strength on pig vesical mucosa. Biol Pharm Bull 2003;26:743-46.

20. Nafee NA, Ismail FA, Boraie NA, Mortada LM. Mucoadhesive delivery systems. II. Formulation and in-vitro/in-vivo evaluation of buccal mucoadhesive tablets containing water-soluble drugs. Drug Dev Ind Pharm 2004;30:995-1004.

21. Khan KA. The concept of dissolution efficiency. J Pharm Pharmacol 1975;27:48-9.

22. Prabhakara P, Malli R, Koland M, Vijaynarayana K, D'Souza U, Harish NM, et al. Formulation and evaluation of fast dissolving films of levocitirizine di hydrochloride. Int J Pharm Investig 2011;1:99-104 